\title{
Asbestos-related diseases in mineworkers: a clinicopathological study
}

\author{
Ntombizodwa Ndlovu ${ }^{1}$, David Rees ${ }^{1,2}$, Jill Murray ${ }^{1,2}$, Naseema Vorajee ${ }^{2,3}$, \\ Guy Richards ${ }^{4}$ and Jim teWaterNaude ${ }^{5}$
}

Affiliations: 'School of Public Health, Faculty of Health Sciences, University of the Witwatersrand, Johannesburg, South Africa. ${ }^{2}$ National Institute for Occupational Health, National Health Laboratory Service, Johannesburg, South Africa. ${ }^{3}$ School of Pathology, Faculty of Health Sciences, University of the Witwatersrand, Johannesburg, South Africa. ${ }^{4}$ Division of Critical Care, Charlotte Maxeke Hospital and Faculty of Health Sciences, University of Witwatersrand, Johannesburg. South Africa. ${ }^{5}$ School of Public Health and Family Medicine, University of Cape Town, Cape Town, South Africa.

Correspondence: Ntombizodwa Ndlovu, School of Public Health, University of the Witwatersrand, 27 St Andrews Road, Parktown 2193, South Africa. E-mail: zodwa.ndlovuawits.ac.za

ABSTRACT The accurate diagnosis of asbestos-related diseases is important because of past and current asbestos exposures. This study evaluated the reliability of clinical diagnoses of asbestos-related diseases in former mineworkers using autopsies as the reference standard.

Sensitivity, specificity, positive predictive value and negative predictive value were calculated.

The 149 cases identified had clinical examinations 0.3-7.4 years before death. More asbestos-related diseases were diagnosed at autopsy rather than clinically: 77 versus 52 for asbestosis, 27 versus 14 for mesothelioma and 22 versus 3 for lung cancer. Sensitivity and specificity values for clinical diagnoses were $50.6 \%$ and $81.9 \%$ for asbestosis, $40.7 \%$ and $97.5 \%$ for mesothelioma, and $13.6 \%$ and $100.0 \%$ for lung cancer. False-negative diagnoses of asbestosis were more likely using radiographs of acceptable (versus good) quality and in cases with pulmonary tuberculosis at autopsy.

The low sensitivity values are indicative of the high proportion of false-negative diagnoses. It is unlikely that these were the result of disease manifestation between the last clinical assessment and autopsy. Where clinical features suggest asbestos-related diseases but the chest radiograph is negative, more sophisticated imaging techniques or immunohistochemistry for asbestos-related cancers should be used. Autopsies are useful for the detection of previously undiagnosed and misdiagnosed asbestos-related diseases, and for monitoring clinical practice and delivery of compensation.

@ERSpublications

Asbestos-related diseases are difficult to diagnose; 58\% diagnosed at autopsy had been missed clinically http://ow.ly/L9u230dr0bv

Cite this article as: Ndlovu N, Rees D, Murray J, et al. Asbestos-related diseases in mineworkers: a clinicopathological study. ERJ Open Res 2017; 3: 00022-2017 [https://doi.org/10.1183/ 23120541.00022-2017].

Received: Feb 212017 | Accepted after revision: July 032017

Support statement: The project was supported by award number D43ES018744 from the US National Institute of Environmental Health Sciences. The content is solely the responsibility of the authors and does not necessarily represent the official views of the National Institute of Environmental Health Sciences or the National Institutes of Health. This publication was facilitated by a writing retreat funded by the University of the Witwatersrand's Strategic Planning and Allocation of Resources Committee (SPARC). Funding information for this article has been deposited with the Crossref Funder Registry.

Conflict of interest: Disclosures can be found alongside this article at openres.ersjournals.com

Copyright $\odot$ ERS 2017. This article is open access and distributed under the terms of the Creative Commons Attribution Non-Commercial Licence 4.0 . 


\section{Introduction}

This study compared clinical and autopsy findings for three asbestos-related diseases (asbestosis, mesothelioma and lung cancer) in former asbestos mineworkers, and explored factors that influenced agreement between clinical and autopsy findings using data from two compensation systems. In South Africa, statutory compensation for occupational lung diseases in mineworkers makes provisions for autopsy examinations of the cardio-respiratory organs at the National Institute for Occupational Health (NIOH) in Johannesburg [1]. In addition, the Johannesburg-based Asbestos Relief Trust and Kgalagadi Relief Trust (the "Trusts") compensate individuals with defined asbestos-related diseases who worked in or lived near qualifying asbestos mining or processing operations [2]. The Trusts also compensate dependents of deceased qualifying mineworkers and therefore encourage statutory autopsies for the detection of previously undiagnosed asbestos-related disease or disease that may have progressed to higher compensation grades.

South Africa was the third largest producer of asbestos and cumulatively produced $97 \%$ of the world's crocidolite [3]. It is among 57 countries that have banned the mining and/or use of all types of asbestos [4]. However, past and current occupational exposures, and nonoccupational domestic and neighbourhood exposures in communities living near asbestos operations, have resulted in a global asbestos-related disease pandemic $[5,6]$.

The reliability of the clinical diagnosis of asbestos-related diseases continues to be important given the large numbers of affected individuals, projections that the asbestos-related disease epidemic is yet to reach its peak and the significant underreporting of asbestos-related diseases $[5,7,8]$. In many parts of the world, benign asbestos-related diseases are often diagnosed based on history, clinical features and chest radiology alone, despite evidence showing that the chest radiograph is inadequate for diagnosis [9, 10]. Similarities between the presenting features of asbestosis and those of other types of diffuse interstitial fibrosis contribute to this unreliability $[9,11]$. The malignant diseases, mainly mesothelioma and lung cancer, require histological and immunohistochemical confirmation as their radiological appearance may be misleading [9, 12-14]. In addition, metastases and infections, such as tuberculosis, may mimic the appearance of mesothelioma and result in misdiagnosis.

Few recent studies have validated chest imaging findings for asbestos-related diseases using the autopsy as the reference standard (table 1). The chest radiograph was shown to underestimate asbestosis and, conversely, to overestimate it when readers were aware of previous asbestos exposure [15, 16]. AKIRA et al. [17] found good correlation between high-resolution computed tomography (HRCT) and autopsy-diagnosed asbestosis. Two other studies showed variability in the proportions of mesothelioma cases confirmed at autopsy [18, 19]. No similar clinicopathological studies were identified for

\section{TABLE 1 Summary of asbestos-related disease clinicopathological studies that compared imaging and autopsy findings}

\begin{tabular}{|c|c|c|c|}
\hline First author [ref.] & Study population & Methods compared & Findings \\
\hline KIPEN [15] & $\begin{array}{l}138 \text { deceased insulation workers } \\
\text { with primary lung carcinoma }\end{array}$ & $\begin{array}{c}\text { Radiology, biopsy and } \\
\text { autopsy }\end{array}$ & False-negative: $18.1 \%$ \\
\hline SLUIS-CREMER [20] & $\begin{array}{l}172 \text { deceased asbestos } \\
\text { mineworkers }\end{array}$ & $\begin{array}{c}\text { Radiological findings of } \\
\text { three readers and } \\
\text { autopsy }\end{array}$ & $\begin{array}{l}67(39.0 \%) \text { autopsy-diagnosed asbestosis cases; for } \\
\text { readers 1, } 2 \text { and 3, respectively: }{ }^{\prime} \text { true-positive: } 38,18 \text { and } \\
\text { 30; false-positive: } 25,5 \text { and } 21 \text {; false-negative: } 29,49 \text { and } \\
\text { 36; true-negative: } 80,100 \text { and } 84 \text {; sensitivity: } 56.7 \%, 26.9 \% \\
\text { and } 45.5 \% \text {; specificity: } 76.2 \%, 95.2 \% \text { and } 80.0 \%\end{array}$ \\
\hline AKIRA [17] & $\begin{array}{c}7 \text { deceased asbestos workers } \\
\text { with radiologically diagnosed } \\
\text { asbestosis }\end{array}$ & $\begin{array}{l}\text { HRCT, biopsy and } \\
\text { autopsy }\end{array}$ & Good correlation between HRCT and autopsy findings \\
\hline MizelL [16] & $\begin{array}{c}273 \text { deceased asbestos workers } \\
\text { with radiologically diagnosed } \\
\text { asbestosis }\end{array}$ & Radiology and autopsy & $\begin{array}{l}\text { True-positive: } 36.8 \% \text { (89 out of } 242 \text { in study group); } \\
\text { false-positive: } 63.2 \% \text { (153 out of } 242 \text { in study group) }\end{array}$ \\
\hline
\end{tabular}


asbestos-related lung cancer. However, one study showed that radiology alone detected fewer cases of lung cancer than when used in conjunction with HRCT and cytology [14].

\section{Materials and methods}

Study subjects

This retrospective, consecutive case series included the records of all former asbestos mineworkers who were clinically examined by the Trusts and had autopsy examinations at the NIOH in 2010 and 2011. No mineworker had occupational asbestos exposure after the clinical evaluation for asbestos-related diseases.

Ethical approval for the study was obtained from the University of the Witwatersrand, Human Research Ethics Committee (M120236) and the University of Michigan Health Sciences and Behavioural Sciences Institutional Review Board (HUM00069012).

\section{Clinical assessment of asbestos-related diseases}

Clinical diagnoses were made by the Trusts' Specialist Occupational Medical Panel (SOMP) that consisted of two radiologists and four occupational medical specialists, three of whom were current or former University of Cape Town medical professors. The SOMP was experienced with occupational lung diseases, and the reading and interpretation of computed tomography images and chest radiographs using the International Labour Office (ILO) classification of chest radiographs [21]. At each session, cases were evaluated by two members of the SOMP (a radiologist and an occupational medical specialist). If the SOMP could not reach a diagnosis, further clinical testing was requested and where there was uncertainty the case was referred to the SOMP Forum, which consisted of all six panellists, for certification.

Posterior-anterior chest radiographs were read according to the ILO methodology, and radiograph quality and any significant radiological changes or abnormalities were recorded [21]. Asbestosis was considered in individuals with small, bilateral irregular linear parenchymal opacities classified as $\mathrm{s}, \mathrm{t}$ or $\mathrm{u}$ of profusion $\geqslant 1 / 0$ in the lower zones of the lungs (with or without extension into the middle and upper zones) [21]. The cut-point of $1 / 0$ was used to distinguish radiographs that were positive for asbestosis from those that were negative [22]. Individuals with radiological features were diagnosed with asbestosis if they had an appropriate occupational history and latency period, clinical findings consistent with asbestosis, and the absence of competing explanations for the observed radiological changes, in accordance with the guidelines of the American Thoracic Society [22]. Chest radiograph quality was categorised according to the ILO criteria for the classification of pneumoconiosis as good, where all criteria were met; acceptable, with few technical defects; acceptable, with defects but still adequate; or unreadable [21]. Only clinical asbestosis cases with good or acceptable radiographs were included in the analyses.

Malignant pleural mesothelioma and lung cancer were diagnosed in individuals with suggestive clinical and radiological findings, usually followed by biopsy of the lesion and confirmation by histology, including immunohistochemistry where available.

\section{Pathological assessment of asbestos-related diseases}

The cardio-respiratory organs were removed with consent at the site where mineworkers died, placed in formalin and sent to the NIOH for examination by specialist anatomical pathologists. The nature and extent of occupational lung diseases, including asbestos-related diseases, were recorded and captured on the Pathology Automation (PATHAUT) database [23].

The presence of asbestos-related diseases was determined by pathological examination of the lungs according to a standard protocol. Slices of lung tissue $(1 \mathrm{~cm}$ thick) were examined macroscopically. Thereafter, a section of the main bronchus with the hilar lymph nodes and a minimum of three sections from each zone of both lungs were taken for microscopic examination. Depending on the pathology identified, additional sections were taken, as appropriate, from areas of the lung with fibrosis or affected by malignancy.

Routine special stains used to assess the degree of fibrosis and detect ferruginous bodies were Gordon and Sweets' reticulin silver and Perl's Prussian blue iron stains, respectively.

The extent of asbestosis was graded using a modification of the grading scheme of CRAIGHEAD et al. [24]. Asbestosis was considered absent if there was no fibrosis; mild where fibrosis was confined to the area around the respiratory bronchioles and the immediately adjacent alveoli; moderate if there was coalescence of fibrosis involving all alveoli between two adjacent bronchioles; and severe if there was widespread fibrosis with the formation of abnormal airspaces or honeycombing.

Pleural malignant mesothelioma and lung cancer were diagnosed based on morphology supported by immunohistochemistry. Calretinin, WT1 (Wilms tumour 1) and CK5/6 (cytokeratin 5/6) were routinely used to confirm mesothelioma. Tumour protein p63 and TTF-1 (thyroid transcription factor-1) were used 
to confirm squamous carcinomas and adenocarcinomas, respectively. The World Health Organization TNM classification was used to determine the pathological stages of mesothelioma and lung tumours that had not been diagnosed in life [25]. For this study, all histology slides and pathology reports were reviewed and confirmed by two pathologists experienced in asbestos-related diseases.

\section{Data collection}

Personal/occupational information, radiology and other clinical findings were obtained from the Trusts' records; pathology findings were obtained from the PATHAUT database. The study did not assess nonmalignant pleural diseases because for many cases the parietal pleurae were not submitted for autopsy. Both clinicians and pathologists were aware of asbestos exposures at the time of examination.

\section{Statistical analysis}

Summary measures are presented as frequencies and percentages or medians and ranges. The Mann-Whitney, Chi-squared and Kruskal-Wallis tests were used to determine statistical differences between and among groups, as appropriate. Statistical significance was defined at $\mathrm{p} \leqslant 0.05$. Specificity, sensitivity, positive predictive value (PPV) and negative predictive value (NPV) were calculated with autopsy findings as the reference standard.

Radiological profusion scores for asbestosis were grouped as none $(0 / 0$ and $0 / 1)$, mild $(1 / 0,1 / 1$ and $1 / 2)$, moderate $(2 / 1,2 / 2$ and $2 / 3)$ and severe $(3 / 2$ and $3 / 3)$. The $\kappa$ statistic was used to test agreement between the clinical and pathological diagnoses. Factors associated with false-negative asbestosis diagnoses were determined using binary logistic regression, with true-positive asbestosis cases as the reference group. Variables with p-values $\leqslant 0.2$ in the univariate analyses were included in the multivariable model. Post-regression analysis was done using the Hosmer-Lemeshow goodness-of-fit test. All analyses were performed using Stata version 13 (StataCorp, College Station, TX, USA).

\section{Results}

There were 149 former asbestos mineworkers, of which 131 (87.9\%) were male. The overall median (range) age at death was $66.1(41.8-95.2)$ years. Most $(n=131(87.9 \%))$ were from the Northern Cape Province, a former crocidolite mining area. First occupational asbestos exposures occurred between 1952 and 1990 (median 1976) and the median (range) latency period (first asbestos exposure to asbestos-related disease diagnosis) was 31.0 (15.0-56.0) years. Approximately one-third had worked in other mining industries, e.g. gold, manganese, platinum and iron.

Based on clinical evaluation, the SOMP diagnosed 52 (34.9\% of the study population) asbestosis cases, 14 (9.4\%) mesothelioma cases and three (2.0\%) lung cancer cases. At autopsy, 77 (51.7\%) cases of asbestosis, $27(18.1 \%)$ cases of mesothelioma and 22 (14.8\%) cases of lung cancer were diagnosed (table 2). Asbestosis was also diagnosed in 10 lung cancer cases and seven mesothelioma cases. The asbestosis cases were older, and had longer employment duration and intervals from first asbestos exposure to death, than those with malignancies. The interval from last clinical assessment to death was shorter compared with lung cancer cases.

Of the 126 asbestos-related diseases diagnosed at autopsy, 73 (57.9\%) were not diagnosed clinically. The low sensitivity values (table 3 ) indicate that most autopsy-diagnosed asbestos-related diseases had not been diagnosed clinically. The specificity, PPV and NPV for asbestosis were lower than those for malignancies (table 3).

\section{TABLE 2 Characteristics of former asbestos mineworkers with asbestos-related diseases diagnosed at autopsy}

\begin{tabular}{|c|c|c|c|}
\hline & Asbestosis & Mesothelioma & Lung cancer \\
\hline Subjects & 77 & 27 & 22 \\
\hline Age at death years & $67.8^{\#}(48.1-93.0)$ & $62.0(44.2-82.7)$ & $65.4(46.8-91.5)$ \\
\hline Employment duration in asbestos mines years & $4.3^{\text {Il }}(0.3-31.0)$ & $3.0(0.3-18.0)$ & $2.0(0.3-20.5)$ \\
\hline Latency years & $36.0(16.0-53.0)$ & $29.0(16.0-56.0)$ & $30.0(15.0-53.0)$ \\
\hline Interval from first asbestos exposure to death years & $41.0^{\# .91}(21.0-58.0)$ & $34.0(21.0-57.0)$ & $35.0(20.0-57.0)$ \\
\hline
\end{tabular}


TABLE 3 Comparison of clinical and autopsy diagnoses of asbestos-related diseases

\begin{tabular}{|c|c|c|c|c|c|c|c|c|}
\hline & True-positive & False-positive & True-negative & False-negative & Sensitivity & Specificity & PPV & NPV \\
\hline Mesothelioma & 11 & 3 & 119 & 16 & 40.7 & 97.5 & 78.6 & 88.1 \\
\hline
\end{tabular}

\section{Asbestosis}

Of the 52 clinical asbestosis diagnoses, 39 were true-positives. The 13 false-positive cases had other lung pathologies at autopsy, i.e. emphysema $(n=2)$, pulmonary tuberculosis (PTB) $(n=2)$, mesothelioma $(n=2)$, both PTB and mesothelioma $(n=1)$, lung cancer $(n=5)$, and pneumonia $(n=1)$.

77 cases had autopsy-diagnosed asbestosis, of which 38 (49.4\%) had false-negative clinical diagnoses. The chest radiographs of the false-negative cases were re-read into the ILO classification by three independent readers who were aware of asbestos exposure but not of the SOMP findings. The median scores for the three readings were $\leqslant 0 / 1(n=30)$ and $\geqslant 1 / 0(n=6)$, and two radiographs had become unreadable. There was good agreement $(83.3 \%)$ between the original and independent readings. Hence, SOMP findings are presented in this paper.

The false-negative cases were significantly younger, and had shorter employment and latency periods than the true-positive cases (table 4). The interval between last clinical assessment and death was not

\begin{tabular}{|c|c|c|c|}
\hline & True-positive & False-negative & p-value \\
\hline Subjects & $39(50.6)$ & $38(49.4)$ & \\
\hline Age at death years & $71.8(51.3-84.3)$ & $66.0(48.1-93.0)$ & 0.00 \\
\hline Employment duration years & $7.0(0.7-41.0)$ & $3.3(0.3-26.6)$ & 0.01 \\
\hline Latency years & $46.0(29.0-58.0)$ & $35.0(21.0-58.0)$ & 0.00 \\
\hline Interval from clinical assessment to death years & $5.7(0.4-7.4)$ & $5.2(0.5-7.4)$ & 0.24 \\
\hline \multicolumn{4}{|l|}{ Chest radiograph quality } \\
\hline Good (grade 1) & 29 & 11 & \multirow[t]{2}{*}{0.00} \\
\hline Acceptable (grades 2 and 3) & 10 & 22 & \\
\hline \multicolumn{4}{|l|}{ Severity of asbestosis ${ }^{\#}$} \\
\hline Mild & 14 & 17 & \multirow[t]{3}{*}{0.05} \\
\hline Moderate & 15 & 16 & \\
\hline Severe & 10 & 5 & \\
\hline \multicolumn{4}{|l|}{ Smoking status } \\
\hline Never-smoker & 21 & 17 & \multirow[t]{2}{*}{0.14} \\
\hline Ex- or current smoker & 15 & 21 & \\
\hline \multicolumn{4}{|l|}{ Other radiological abnormalities } \\
\hline Present & 29 & 27 & \multirow[t]{2}{*}{0.74} \\
\hline Absent & 10 & 11 & \\
\hline \multicolumn{4}{|l|}{ Mesothelioma" } \\
\hline Present & 3 & 4 & \multirow[t]{2}{*}{$0.71^{9}$} \\
\hline Absent & 36 & 34 & \\
\hline \multicolumn{4}{|l|}{ Lung cancer $\#$} \\
\hline Present & 3 & 7 & \multirow[t]{2}{*}{0.19 9 } \\
\hline Absent & 36 & 31 & \\
\hline \multicolumn{4}{|l|}{ Emphysema\# } \\
\hline Present & 15 & 13 & \multirow[t]{2}{*}{0.70} \\
\hline Absent & 24 & 25 & \\
\hline \multicolumn{4}{|l|}{ PTB $^{\#}$} \\
\hline Present & 5 & 11 & \multirow[t]{2}{*}{0.08} \\
\hline Absent & 34 & 27 & \\
\hline
\end{tabular}

Data are presented as $\mathrm{n}(\%)$, median (range) or $\mathrm{n}$, unless otherwise stated. PTB: pulmonary tuberculosis.

\#: autopsy diagnosis; " : Fischer's exact test. 
significantly different. Using tertiles of this interval, we found that although the sensitivity values for asbestosis increased with increasing interval, the differences were not significant.

Compared with true-positive asbestosis cases, the likelihood of false-negative diagnoses was significantly higher in cases with acceptable radiographs (versus good) and in those with autopsy-diagnosed PTB (table 5).

There was poor agreement $(47.0 \% ; \kappa=0.15)$ between the severity of radiological and autopsy-diagnosed asbestosis. Of the 72 individuals who did not have asbestosis at autopsy, 12 had mild asbestosis (1/0, 1/1 and $1 / 2$ ) and one had severe asbestosis (3/3) (table 6). Of the 39 true-positive cases, 27 had more severe disease at autopsy. Nine cases had severe asbestosis at autopsy and profusion scores of $\leqslant 1 / 0$. Of these, two had normal spirometry, and restrictive patterns in the remaining cases were mild $(n=1)$, moderate $(n=3)$ and severe $(n=3)$.

\section{Asbestos-related cancer}

27 cases of mesothelioma and 22 cases of lung cancer were diagnosed at autopsy. 14 (28.6\%) malignancies had been correctly diagnosed clinically, resulting in low sensitivity values (table 3 ). Specificity values were high with no false-positive diagnoses of lung cancer. The three false-positive cases of mesothelioma were diagnosed as large $(n=1)$ and squamous cell $(n=2)$ carcinomas at autopsy. All clinical diagnoses were confirmed using histology and immunochemistry, except for two mesothelioma cases: one refused biopsy and another died while undergoing investigation. HRCT was used to diagnose two of the true-positive malignancies.

There were 35 false-negative diagnoses of malignant disease. The 16 mesothelioma cases and 19 lung cancer cases had last been examined 4.8 years (range 0.3-6.3 years) and 4.4 years (range 0.7-7.0 years) before death, respectively. 24 of the cases had benign asbestos-related diseases (11 had asbestosis, four had pleural disease, and nine had both asbestosis and pleural disease). Seven false-negative cases (five mesotheliomas and two lung cancers) died while undergoing investigation.

Three of the 16 false-negative mesotheliomas were from lungs that were received piecemeal. The pathological classification of four of the mesotheliomas was T2 (with confluent visceral pleural tumours), one of which also had invasion of the lung parenchyma. 12 were T4 with direct extension to the contralateral pleura and/or invasion of the myocardium. The thickness of the mesotheliomas was $<10$ $(n=1), 10-20(n=7)$ and $\geqslant 30 \mathrm{~mm}(n=8)$. Four of the 19 false-negative primary lung cancers were from lungs that were received piecemeal and could not be classified. The lung cancers were classified as $\mathrm{T} 1 \mathrm{~b}$ $(\mathrm{n}=1)$, T2 $(\mathrm{n}=4)$, T3 $(\mathrm{n}=8)$ and T4 $(\mathrm{n}=2)$. One lung cancer was $>30 \mathrm{~mm}$ in diameter and the remainder were $>70 \mathrm{~mm}$.

\section{Discussion}

This study provides recent clinicopathological findings on three asbestos-related diseases in former asbestos mineworkers using autopsies as the reference standard for comparison. The major finding was that many diagnoses had been missed clinically.

One limitation of this study is the interval (0.3-7.4 years) between the last clinical assessment and death. This might explain the large proportion of false-negative cancer diagnoses, as tumours may have developed and progressed rapidly during this interval and/or manifested clinical symptoms late [26]. This

TABLE 5 Factors associated with false-negative diagnoses of asbestosis

\begin{tabular}{lcc} 
& Odds ratio $(95 \%$ CI) & p-value \\
\hline Age at death years & $0.95(0.87-1.03)$ & 0.24 \\
Employment duration years & $0.93(0.86-1.02)$ & 0.14 \\
Latency years & $1.01(0.93-1.10)$ & 0.78 \\
Smoking & $2.08(0.48-9.08)$ & 0.33 \\
Chest radiograph quality & $12.33(2.54-59.72)$ & 0.00 \\
$\quad$ Acceptable versus good & $1.18(0.24-5.71)$ & 0.84 \\
Severity of asbestosis & $0.26(0.04-1.73)$ & 0.16 \\
$\quad$ Moderate versus mild & $3.17(0.39-25.80)$ & 0.28 \\
$\quad$ Severe versus mild & $8.45(1.16-61.69)$ & 0.04 \\
Lung cancer at autopsy & & \\
PTB at autopsy & & \\
\hline PTB: pulmonary tuberculosis. & & \\
\hline
\end{tabular}


TABLE 6 Agreement between the severity of radiological and autopsy diagnoses of asbestosis

\begin{tabular}{|c|c|c|c|c|c|}
\hline \multirow[t]{2}{*}{ Radiological asbestosis } & \multicolumn{4}{|c|}{ Pathological asbestosis } & \multirow[t]{2}{*}{ Total } \\
\hline & None & Mild & Moderate & Severe & \\
\hline \multicolumn{6}{|l|}{ None } \\
\hline $0 / 0$ & 43 & 11 & 11 & 4 & 69 \\
\hline $0 / 1$ & 16 & 6 & 5 & 1 & 28 \\
\hline \multicolumn{6}{|l|}{ Mild } \\
\hline $1 / 0$ & 10 & 7 & 3 & 4 & 24 \\
\hline $1 / 1$ & 1 & 1 & 8 & 4 & 14 \\
\hline $1 / 2$ & 1 & 1 & 2 & 2 & 6 \\
\hline \multicolumn{6}{|l|}{ Moderate } \\
\hline $2 / 1$ & 0 & 1 & 0 & 1 & 2 \\
\hline $2 / 2$ & 0 & 0 & 2 & 2 & 4 \\
\hline $2 / 3$ & 0 & 0 & 0 & 1 & 1 \\
\hline \multicolumn{6}{|l|}{ Severe } \\
\hline $3 / 3$ & 1 & 0 & 0 & 0 & 1 \\
\hline Total & 72 & 27 & 31 & 19 & 149 \\
\hline
\end{tabular}

could also explain the poor agreement between the clinical and autopsy grading of asbestosis but this is unlikely, as discussed later.

The proportion (49.4\%) of false-negative asbestosis diagnoses is higher than that reported for interstitial fibrotic lung diseases (10-20\%) [22, 27-29]. The sensitivity value for asbestosis is within the range of 26.9-56.7\% reported for deceased South African asbestos mineworkers [20]. False-negative asbestosis diagnoses may have occurred because the Trusts used radiological detection of opacities as the entry point for investigation of asbestosis and, as such, a negative reading would preclude further investigation. The missed diagnoses were not due to poor interpretation of films by the SOMP as its findings were confirmed by three independent readers.

The false-negative cases may have arisen from progression in the interval between the clinical and autopsy examinations. Progression from normal to radiologically detectable asbestosis, even long after exposure cessation, is well established and occurs in a minority of amphibole exposed workers [30-32]. The determinants of progression include cumulative asbestos exposure, intensity of exposure, duration of follow-up and age, but vary among study cohorts [30-33]. Asbestosis developed in $10.6 \%$ of former South African mineworkers 5.7 years after exposure cessation and in $4-10 \%$ of former US amosite factory workers after $\geqslant 10$ years [31-33]. As in our study, the workers had been exposed to amphibole asbestos (amosite and/or crocidolite), but decades earlier and after shorter asbestos exposures [31-33]. Hence, progression rates reported elsewhere may not be directly applicable to our setting.

Diagnostic accuracy may be improved by having serial chest radiographs, but we did not have the data to examine this. HRCT, a more sensitive tool for asbestosis diagnosis, is particularly useful where there are no or indeterminate radiological findings $(0 / 0$ or $0 / 1)$ in symptomatic, exposed individuals with abnormal lung function $[22,26]$. It reduces false-positive diagnoses through identification of other pleural and parenchymal conditions, e.g. emphysema and bronchiectasis, which may explain radiological changes thought to be asbestosis [22, 34]. Nonetheless, HRCT may miss disease, detect nonspecific changes unrelated to asbestosis and is prone to inter-reader variability [10,35]. In settings with limited access to HRCT, patients with asbestos exposure and clinical features of asbestosis, including exertional dyspnoea, crackles on auscultation of the chest and abnormal lung function tests, particularly chest restriction or reduced transfer factor of the lung for carbon monoxide, should be prioritised for imaging [22].

The second limitation is the small number of cases available to determine factors associated with false-negative asbestosis diagnoses. Hence, some explanatory variables may not have been identified. Nonetheless, our findings suggest that asbestosis is more likely to be diagnosed using radiographs of good quality and less likely in cases with PTB.

There were few false-positive diagnoses of asbestosis and mesothelioma, and none of lung cancer. The specificity of asbestosis (81.6\%) is similar to that observed in a previous study (76.2-80.0\%) [20]. Factors associated with false-positive asbestosis readings include radiographic technique, aging, obesity, smoking, presence of chronic obstructive pulmonary disease and dust exposures [10, 20]. We found that the false-positive cases had other pathologies ( $\mathrm{PTB}$, emphysema or lung cancer) that could have been misread as asbestosis. 
Most of the 35 cases with false-negative malignancies had advanced tumours at autopsy. Although seven malignancies were suspected in life, the cases died before a definitive diagnosis was made. The predominantly advanced pathological stage of the tumours suggests that there could have been more true-positive clinical diagnoses if clinicians had a higher index of suspicion and had been more aggressive in investigating these tumours. Accuracy could be improved by the introduction of standardised protocols for immunohistochemistry panels for mesothelioma and lung cancer in peripheral pathology laboratories.

\section{Conclusions}

This study confirms that chest radiography, as the sole imaging tool in asbestos-exposed individuals, substantially underdiagnoses asbestos-related diseases but has good specificity, producing few false-positive results. Accurate clinical diagnoses ensure timely management and treatment of diseases that present similarly to asbestos-related diseases, and provide more reliable incidence and prevalence estimates to inform prevention strategies [8]. Increased diagnostic awareness among healthcare providers is necessary for asbestos-related disease diagnosis, particularly in the poorly resourced public healthcare facilities to which many South Africans present [36]. This study highlights the valuable role of autopsies in the detection of undiagnosed disease, monitoring of clinical practice and delivery of compensation.

\section{Acknowledgements}

The authors thank Thandikhaya Mgoqi (Asbestos Relief Trust, Cape Town, South Africa) for assistance with data collation and the Trustees of the Asbestos and Kgalagadi Relief Trusts (Johannesburg, South Africa) for their support.

Author contributions: N. Ndlovu: substantial contributions to the conception and design of the work, and the acquisition, analysis and interpretation of data. D. Rees: substantial contributions to the analysis and interpretation of data. J. Murray: substantial contributions to the conception and design of the work, and analysis and interpretation of data. N. Vorajee and G. Richards: substantial contributions to the interpretation of data. J. teWaterNaude: substantial contributions to the conception of the work, and acquisition and interpretation of data. All authors: drafting the work or revising it critically for important intellectual content; final approval of the version to be published; agreement to be accountable for all aspects of the work in ensuring that questions related to the accuracy or integrity of any part of the work are appropriately investigated and resolved.

\section{References}

1 Republic of South Africa. Occupational Disease in Mines and Works Act No. 78 of 1973. Government Printer, Pretoria, 1973.

2 Asbestos Relief Trust. Asbestos and Asbestos Compensation Schemes in South Africa. Johannesburg, Asbestos Relief Trust, 2009.

3 McCulloch J. Asbestos mining in Southern Africa, 1893-2002. Int J Occup Environ Health 2003; 9: 230-235.

4 International Ban Asbestos Secretariat. Current Asbestos Bans and Restrictions. 2015. www.ibasecretariat.org/ alpha_ban_list.php Date last accessed: August 11, 2016.

5 Park EK, Takahashi K, Jiang Y, et al. Elimination of asbestos use and asbestos-related diseases: an unfinished story. Cancer Sci 2012; 103: 1751-1755.

6 Ndlovu N, teWater Naude J, Murray J. Compensation for environmental asbestos-related diseases in South Africa: a neglected issue. Glob Health Action 2013; 6: 19410.

7 Takahashi K, Landrigan PJ. The global health dimensions of asbestos and asbestos-related diseases. Ann Glob Health 2016; 82: 209-213.

8 Park EK, Takahashi K, Hoshuyama T, et al. Global magnitude of reported and unreported mesothelioma. Environ Health Perspect 2011; 119: 514-518.

9 Roggli VL, Gibbs AR, Attanoos R, et al. Pathology of asbestosis - an update of the diagnostic criteria: report of the Asbestosis Committee of the College of American Pathologists and Pulmonary Pathology Society. Arch Pathol Lab Med 2010; 134: 462-480.

10 Ross RM. The clinical diagnosis of asbestosis in this century requires more than a chest radiograph. Chest 2003; 124: $1120-1128$.

11 Tossavainen A. Asbestos, asbestosis, and cancer: the Helsinki criteria for diagnosis and attribution. Scand J Work Environ Health 1997; 23: 311-316.

12 Betta PG, Magnani C, Bensi $\mathrm{T}$, et al. Immunohistochemistry and molecular diagnostics of pleural malignant mesothelioma. Arch Pathol Lab Med 2012; 136: 253-261.

13 Rudd RM. Malignant mesothelioma. Br Med Bull 2010; 93: 105-123.

14 Hamada K, Tokuyama T, Okamoto $\mathrm{Y}$, et al. A clinicopathological study of lung cancer patients with occupational exposure to chrysotile asbestos fibers. Intern Med 1999; 38: 780-784

15 Kipen HM, Lilis R, Suzuki Y, et al. Pulmonary fibrosis in asbestos insulation workers with lung cancer: a radiological and histopathological evaluation. Br J Ind Med 1987; 44: 96-100.

16 Mizell KN, Morris CG, Carter JE. Antemortem diagnosis of asbestosis by screening chest radiograph correlated with postmortem histologic features of asbestosis: a study of 273 cases. J Occup Med Toxicol 2009; 4: 14.

17 Akira M, Yamamoto S, Yokoyama K, et al. Asbestosis: high-resolution CT-pathologic correlation. Radiology 1990; 176: 389-394.

18 Takeshima Y, Inai K, Amatya VJ, et al. Accuracy of pathological diagnosis of mesothelioma cases in Japan: clinicopathological analysis of 382 cases. Lung Cancer 2009; 66: 191-197.

19 Yates DH, Corrin B, Stidolph PN, et al. Malignant mesothelioma in south east England: clinicopathological experience of 272 cases. Thorax 1997; 52: 507-512.

20 Sluis-Cremer GK, Hessel PA, Hnizdo E. Factors influencing the reading of small irregular opacities in a radiological survey of asbestos miners in South Africa. Arch Environ Health 1989; 44: 237-243. 
21 International Labour Office. Guidelines for the Use of the ILO International Classification of Radiographs of Pneumoconioses. Geneva, International Labour Office, 2011.

22 American Thoracic Society. Diagnosis and initial management of nonmalignant diseases related to asbestos. Am J Respir Crit Care Med 2004; 170: 691-715.

23 Ndlovu N, Nelson G, Vorajee N, et al. 38 years of autopsy findings in South African mine workers. Am J Ind Med 2016; 59: 307-314.

24 Craighead JE, Abraham JL, Churg A, et al. The pathology of asbestos-associated diseases of the lungs and pleural cavities: diagnostic criteria and proposed grading schema. Report of the Pneumoconiosis Committee of the College of American Pathologists and the National Institute for Occupational Safety and Health. Arch Pathol Lab Med 1982; 106: 544-596.

25 Travis WD, Brambilla E, Burke AP, et al., eds. WHO Classification of Tumours of the Lung, Pleura, Thymus and Heart. Lyon, IARC, 2015.

26 Tossavainen A. International expert meeting on new advances in the radiology and screening of asbestos-related diseases. Scand J Work Environ Health 2000; 26: 449-454.

27 Copley S, Hansell DM. Imaging. In: Hendrick DJ, Burge PS, Beckett WS, et al., eds. Occupational Diseases of the Lung: Recognition, Management and Prevention. WB Saunders, London, 2002; pp. 483-501.

28 Parker JE. Radiological criteria: the use of chest imaging techniques in asbestos-related diseases. People Work Res Rep 1997; 14: 28-40.

29 Epler GR, McLoud TC, Gaensler EA, et al. Normal chest roentgenograms in chronic diffuse infiltrative lung disease. N Engl J Med 1978; 298: 934-939.

30 Cookson WO, De Klerk NH, Musk AW, et al. Prevalence of radiographic asbestosis in crocidolite miners and millers at Wittenoom, Western Australia. Br J Ind Med 1986; 43: 450-457.

31 Ehrlich R, Lilis R, Chan E, et al. Long term radiological effects of short term exposure to amosite asbestos among factory workers. Br J Ind Med 1992; 49: 268-275.

32 Shepherd JR, Hillerdal G, McLarty J. Progression of pleural and parenchymal disease on chest radiographs of workers exposed to amosite asbestos. Occup Environ Med 1997; 54: 410-415.

33 Sluis-Cremer GK, Hnizdo E. Progression of irregular opacities in asbestos miners. Br J Ind Med 1989; 46: 846-852.

34 Wolff $\mathrm{H}$, Vehmas $\mathrm{T}$, Oksa $\mathrm{P}$, et al. Asbestos, asbestosis, and cancer, the Helsinki criteria for diagnosis and attribution 2014: recommendations. Scand J Work Environ Health 2015; 41: 5-15.

35 Miller A, Widman SA, Miller JA, et al. Comparison of x-ray films and low-dose computed tomographic scans: demonstration of asbestos-related changes in 2760 nuclear weapons workers screened for lung cancer. J Occup Environ Med 2013; 55: 741-745.

36 Kgalamono SM, Rees D, Kielkowski D, et al. Asbestos in the non-mining industry on the Witwatersrand, South Africa. S Afr Med J 2005; 95: 47-51. 